ISSN: 2162-3104 Print/ ISSN: 2166-3750 Online

Volume 8, Issue 1 (2018), pp. 21-37

(C) Journal of International Students

http://jistudents.org/

doi: $10.5281 /$ zenodo. 1101028

\title{
Measuring College Success for International Baccalaureate Diploma and Certificate Candidates
}

\author{
Jennifer Coles Hill \\ Northwest Nazarene University, United States
}

\begin{abstract}
This quantitative study was conducted at a private international high school. The study purpose was to investigate United States college trends comparing International Baccalaureate Diploma Program candidates and International Baccalaureate Non-Diploma Program candidates from the same school in Asia. Data was collected for the Classes of 2007-2012 and the two groups were compared based on the number of college acceptances and the eventual collegiate success of the two groups once they matriculated to college, as measured by college persistence and graduation rates. The information analyzed provides data to explore the final educational outcomes for International Baccalaureate graduates and determine if there is a significant difference in the college success of the two groups.
\end{abstract}

Keywords: college admission, graduation rates, International Baccalaureate, international students

Numerous studies have been conducted which show a rigorous high school course of study contributes to academic success in college for both domestic and international students (Adelman, 2006; Breland, Maxey, Gernand, Cumming, \& Trapani, 2002; Geiser, 2008; Geiser \& Santelices, 2004). The International Baccalaureate Program is one type of specific high school curriculum that has been linked to success in college (Bergeron, 2015; Caspary \& Bland, 2011; Duevel, 1999; Shah, Dean, \& Chen, 2010; Thomas, 1991). However, within the worldwide International Baccalaureate (IB) 
curriculum, there are two different paths available to students: the full IB Diploma Program (IBDP) and the certificate program track (IBO, 2017) The IBDP consists of six IB courses (three standard level and three higher level courses) completed over a 2-year period for juniors and seniors, in addition to a three-semester Theory of Knowledge course and a 4,000-word extended essay on a topic of the students' choosing. Each diploma candidate must also complete at least $150 \mathrm{hr}$ of self-directed volunteer work over the 2-year period in the categories of creativity, action, and service (Chmelynski, 2005; IBO, 2017).

Within the IB curriculum, not every student has the ability or scope of knowledge to qualify for an IBDP schedule and excel in six different subject areas, including a second language (Chmelynski, 2005; GazdaGrace, 2002; IBO, 2017). In many IB schools, students who are either academically unqualified or unwilling to take the six IB courses (plus Theory of Knowledge) required for a full IB diploma are able to take individual IB certificates in the IB courses appropriate for their learning and ability levels (IBO, 2017). Additionally, since the pursuit of an IB diploma or individual certificates requires a commitment to a 2-year course of study, the program choice usually has to be made during a student's sophomore year. Students often feel ill equipped and unprepared to make such an important decision so early in their high school careers (Mayer, 2008; Taylor \& Porath, 2006).

As popular as the IB curriculum has become, few studies have been conducted to compare college acceptance and completion rates for IBDP candidates versus certificate students (Caspary, 2011). Almost all of the research currently available on college admission and success for IB students is based on research studies commissioned and sponsored by the International Baccalaureate Organization (Bergeron, 2015; Caspary, 2011; Caspary \& Bland, 2011; Shah et al., 2010), and there is an important academic need for IB research to be conducted outside of the umbrella of the IBO.

Furthermore, at the collegiate level, if highly competitive colleges and universities in the United States are using IBDP participation as a factor in college admission, it is important to study the eventual collegiate success of those students in comparison to their non-DP peers to ascertain if there are noticeable differences between the two groups.

Both new and well-established international schools using the IB curriculum are faced with the same dilemma-is it more advantageous to require all high school juniors and seniors to take the full IB Diploma, or should students have a certificate option? Will students who take the less- 
rigorous certificate route have fewer college acceptances? Are students who do not take the full IBDP less likely to graduate from the college they attend in the United States than their full IB Diploma peers? In essence, if a student attends an IB high school, is a full diploma schedule necessary to be accepted into a U.S. college or university and a factor in student success once the student matriculates? These are the important and high-stakes questions routinely asked in the classrooms and counseling offices of international schools around the world, and this study adds more concrete data to the discussion.

\section{LITERATURE REVIEW}

The decision to attend college in the United States is rarely coincidental or happenstance. International students view a U.S. degree as their primary route to future personal and professional success and they begin planning their college programs and the paths to get there years before they actually apply (Borden, 2005; Chen, 1999; Kim, 2011; Park, 2009; Zhang \& Hagedorn, 2011).

So how then can we measure the academic rigor of high school courses for international students and predict their college success? One way is to examine a common high school curriculum used by schools in multiple countries and compare the rigor of the different high school programs of study to the students' later college success. The International Baccalaureate Program is one such curriculum that can be used for data collection purposes in the context of international student college success factors and high school course-of-study predictors.

The International Baccalaureate ${ }^{\circledR}$ (IB) was founded in 1968 in Geneva, Switzerland. The program was originally developed for students from ages 3-19 who were internationally mobile and wanted to prepare to participate in higher education in an English-speaking country. The first IB schools were predominantly private, but today just over half of the IB World Schools authorized to offer the Primary Years Program (for students aged 312), Middle Years Program (for students aged 11-16), and/or the Diploma Program (for students aged 16-19) are public schools (IBO, 2017). Bunnell (2008) reported in the United States, 92\% of the IB World Schools were state-funded. In October 2017, there were 6,282 programs being offered worldwide across 4,775 schools. This represents a growth of $39.3 \%$ over the last 5 years (IBO, 2017).

In May 1990, a total of 301 IB schools administered IB exams to 13,122 students. From that group, 4,263 were IBDP candidates. Twenty-six 
years later, in May 2016, a total of 2,487 IB schools from 136 countries administered IB examinations to 149,446 students. From that group, 74,581 were IBDP candidates ("IB Statistical Bulletin," 2016).

Unlike Advanced Placement exams, IB students must be enrolled in the specific IB course to be eligible to take the examination for that subject. IB exams are knowledge-based (students are evaluated on what they have actually studied) and criterion-referenced (Chmelynski, 2005; Gazda-Grace, 2002; IBO, 2017). The variety and quality of assessments are what further separates the International Baccalaureate from other curricula. Students in English, for example, must also complete an internal assessment component that is an individual oral commentary. The teacher selects a literary passage that has been previously studied and the student is given a short time to read the passage and take notes. Then, the student must individually complete a recorded dialogue with the teacher regarding the meaning of the selection. The conversation is scored based on an international rubric and select recordings are then sent to different locations around the world to be externally moderated and assessed by IB examiners. When final IB exams are graded each summer by the IBO, schools receive subject reports listing student scores for the individual school and worldwide. Each teacher receives a written report from the subject examiner explaining how well his/her students were prepared for the exam and offering the individual teacher specific curriculum and instruction suggestions (Gazda-Grace, 2002). Because of its rigorous and highly structured and regulated comprehensive curriculum, coupled with the ongoing intensive teacher training, the program has grown into what has been called the "Cadillac" of college-prep programs (Gehring, 2001).

Thomas (1991) offered one of the first early studies on IB and college success when he followed 1,036 IB diploma holders at 26 U.K. universities who sat for university examinations from 1971-1987. His results showed $98 \%$ of the diploma holders completed good honours degrees (meaning the students graduated with first, second, or third class honours, similar to the U.S. summa cum laude, magna cum laude, and cum laude honors designations). Duevel (1999) examined whether earning an IB Diploma in high school was a predictor of later university success. She worked with twelve U.S. universities as part of her doctoral dissertation (Columbia, Cornell, Georgia Tech, Harvard, Indiana at Bloomington, Texas at Austin, Illinois at Urbana-Champaign, Virginia, Washington, and Wisconsin at Madison) and found $92 \%$ of their IB Diploma holders earned bachelor's degrees and $87 \%$ of those degrees were earned in 5 years or less. 
Bergeron (2015) reported that of the 13,555 students in public and private high schools in the United States who took IB exams in 2008, $78 \%$ enrolled in U.S. postsecondary institutions immediately, compared to $69 \%$ immediate enrollment by their non-IB peers. The first year retention rate was $98 \%$, compared to the national rate of $77 \%$. The average 4 -year college graduate rate was $79 \%$.

In many IB schools, students who are unable or unwilling to take the six IB courses (plus Theory of Knowledge) required for a full IB diploma are able to earn individual IB Certificates in the IB courses appropriate for their learning and ability levels (IBO, 2017). In another study commissioned by the IB through SRI International, worldwide data was collected from 2001 and 2002 in IB schools for 1,919 students who took between one and six IB classes as juniors and seniors in an international high school. Years later, 1,126 of the 1,919 students from international IB high schools attended college in the United States and had the following completion rates: $75 \%$ of the IB Diploma recipients $(n=799)$ graduated from college within 4 years, and a total of $85 \%$ of the diploma recipients graduated within 6 years; $55 \%$ of the IB Certificate students $(n=$ 295) graduated from college after 4 years, and $80 \%$ graduated within six years of enrolling (Caspary, 2011).

Of the highest achieving students who scored a six or a seven on three or more exams (seven being the highest score possible), $81 \%$ graduated within 4 years; after 6 years, $91 \%$ of the students in this group had graduated from the U.S. college or university where they matriculated directly after high school. There was also a small group of non-diploma recipients in the sample group $(n=32)$ who attempted the IB diploma but did not complete it successfully, and data from those students showed $41 \%$ graduated in 4 years and 66\% percent graduated in 6 years (Caspary, 2011). It is important to note even though this study was conducted with students at international high schools, the students in the study all claimed "American" as their first or second nationality on their IB exam registrations. Therefore, these students would have applied to U.S. colleges as domestic students and would not be considered international students for college data purposes.

Taylor and Porath (2006) completed a qualitative study on the reflections of recent IB graduates and interviewed 16 students from schools in British Columbia. They found that overall, students had a positive experience and felt the IB gave them an intellectually stimulating curriculum and prepared them well for post-secondary education. Eightyseven percent of the respondents felt they were better prepared for postsecondary education than their non-IB peers, and $68.75 \%$ felt better 
prepared for advanced college courses. Sixty-two and a half percent of the students surveyed were granted some kind of credit in college for their high school IB coursework. However, only half of the students surveyed reported feeling less stressed their first year in college than they perceived their nonIB-educated peers to be.

Caspary and Bland (2011) conducted another study for SRI International, which analyzed the first college courses taken by 4,845 Florida students who took the senior IB exams between 2000 and 2005 and enrolled at the University of Florida the fall after their senior year in high school. Overall, seniors who performed well on their IB subject exams earned higher college grades in the same subjects than students who did not perform as well on the IB exams. For example, 59 percent of students in the sample group who earned a final score of six or seven (seven being the highest score possible) on a specific IB subject exam earned a final grade of A in their first college course in that subject.

Shah, Dean, and Chen (2010) examined the success of 1,547 IB Diploma students in the United States who enrolled in a University of California college between 2000 and 2002. They compared the group to the entire UC student population as well as to a comparison group of 5,253 nonIB students with similar profiles in the areas of enrollment, family income, race, and high school performance using GPA and highest SAT or ACT score. The results of the descriptive analysis showed IB students had higher college grade point averages and higher graduation rates than both the comparison group and the overall UC student population. The regression analysis (with controls for socio-economic status, ACT/SAT, and high school grade point average) showed a positive relationship between IB participation and college performance. DP performance (as measured by final IB scores) was the best predictor of college success and accounted for approximately $25 \%$ of the variance. The scores on the IB science exams were the best predictors of college GPA, demonstrating $17 \%$ of the variance.

It is important to note the Bergeron (2015), Caspary (2011), Caspary and Bland (2011), and Shah et al. (2010) studies were directly commissioned by the International Baccalaureate and were not peer reviewed or published outside of the International Baccalaureate Organization. Therefore, these studies have not undergone the same scrutiny that would exist with a peer-reviewed study. There is a definite research hole found in this area because there are few IB studies that have been conducted independently and outside of the control and authorization of IBO. 


\section{RESEARCH METHOD}

This quantitative study compares the college application submission and acceptance rates for IB Diploma candidates and IB Certificate candidates at the same international school. After both groups matriculate to college, college persistence rates (freshman to sophomore) and the number of years that each of the two groups spend in college prior to graduation are compared. Data is analyzed from the two groups to answer the following question-How do IB Diploma candidates and IB Certificate candidates compare in college application, admission, and graduation rates?

\section{Participants}

This study was conducted at a private urban international $\mathrm{K}-12$ school in East Asia, which annually sends approximately $95 \%$ of its graduates to colleges and universities in the United States of America. The study school is accredited by the Western Association of Schools and Colleges (WASC) and is fully authorized to offer the IB Diploma Program. The school transitioned from using the Advanced Placement curriculum to the IB curriculum in 2005, and had its first class of IB Diploma and Certificate candidates graduate in 2007.

Approximately 500 students from 22 nations attend the school, with $46 \%$ of the students holding passports from the United States and 39\% holding passports from Korea. Currently $84 \%$ of students have ethnic Asian backgrounds. The student-to-teacher ratio is $6: 1$. For the graduating Class of 2012, the 93 students in the senior class received 323 college acceptance offers and accumulated \$4,656,097 USD in scholarship offers from 140 universities around the world. The school is known for its academic rigor and its high acceptance rates to selective colleges in the United States and worldwide.

Data was collected for approximately 550 graduates who graduated from the study school between 2007 and 2012. Specifically, the researcher collected and analyzed variables with data gathered from Naviance, IBIS, and the National Student Clearinghouse.

Naviance is a college and career planning and data tool created by Hobsons and available to secondary schools as part of an annual paid subscription. Students can research college acceptance data specific to their school's applicants as well as worldwide statistics. Students report their individual acceptances into the database for tracking purposes each year (Naviance, 2017). The study school also uses Naviance's edocs feature to 
transmit school documents (transcript, letters of recommendation, etc.) electronically to colleges around the world.

From the Naviance database, the researcher collected the number of college applications that each individual student in the graduating classes of 2007-2012 submitted, along with the number of acceptance offers he or she received, as were recorded previously in the database.

IBIS is a planning, assessment, and reporting tool developed and maintained by the IBO in Geneva, Switzerland, that is available to schools as part of their IB affiliation. IBIS is a password-protected secure website for IB schools and IB site coordinators and school counselors use this site to register candidates, submit predicted grades internal assessment marks, and receive results (IBO, 2017).

IBIS was used in this study to determine the country of origin, course selection, and diploma type (diploma or certificate) for each student in each graduating class from 2007-2012. Data was retrieved from IBIS in the form of .pdf documents listing the name, country of origin, and diploma type of every student by class.

The National Student Clearinghouse's StudentTracker for High School system matches alumni records to collegiate enrollment and degree data for U.S. colleges and universities. For an annual subscription fee, schools receive FERPA-compliant detailed reports on college trends by graduating class and the post-secondary performance of individual students (National, 2017). The researcher submitted the names, birthdates, and graduation dates for all of its students in the graduating classes of 20072012 to the National Clearinghouse. The results were electronically delivered to the study school in the form of Excel and .pdf documents and the researcher combined the matriculation, retention, and college graduation data with the information that had already been collected and saved from the Naviance and IBIS databases.

\section{RESULTS}

As illustrated by the data in Table 1, for the graduating classes of 20072012 at the study school, IB Diploma candidates $(n=192)$ submitted a mean number of 9.182 college applications $(S D=4.963 ; S E M=0.358)$. IB Certificate candidates $(n=349)$ submitted a mean number of 7.115 college applications $(S D=4.564 ; S E M=0.224)$. The Independent $t$ test for equality of means shows a mean difference between the two groups of 2.067 applications. 
Table 1. Mean number of college applications and college acceptances, 2007-2012.

\begin{tabular}{lcc}
\hline & $\begin{array}{c}\text { IB diploma } \\
\text { candidates }\end{array}$ & $\begin{array}{c}\text { IB certificate } \\
\text { candidates }\end{array}$ \\
\hline Mean number of college applications submitted & 9.182 & 7.115 \\
Mean number of college acceptances & 4.063 & 3.418 \\
\hline
\end{tabular}

Note. IB = international baccalaureate.

The $t$-test revealed a statistically reliable difference between the mean number of college applications for the IB Diploma candidates $(M=$ 9.182, $s=4.963)$ and for the IB Certificate candidates $(M=7.115, s=$ 4.564), $t(539)=4.769, p<0.001, \alpha=0.05$.

In calculating effect size using Omega-squared, the value indicates that about $3 \%$ of the difference between the groups of students can be explained by diploma type.

$$
u^{2}=\frac{t^{2}-1}{i^{2}+\pi_{1}+n_{2}-1}=\frac{22.713-1}{22.713+192+314-2}=\frac{21.713}{362.713}=.039
$$

In calculating effect size using Cohen's d, the value indicates that the effect size is small.

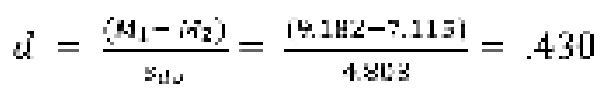

IB Diploma candidates $(n=192)$ received a mean number of 4.063 college acceptances $(S D=2.436 ; S E M=0.176)$. IB Certificate candidates $(n$ $=349)$ received a mean number of 3.418 college acceptances $(S D=2.548$; $S E M=0.136)$. The Independent $t$ test for equality of means shows a mean difference between the two groups of 0.644 acceptances.

The $t$-test revealed a statistically reliable difference between the mean number of college acceptances the IB Diploma candidates had $(M=$ 4.063, $s=2.436)$ and the IB Certificate candidates had $(M=3.418, s=$ $2.548), t(539)=2.858, p=.004, \alpha=.05$.

In calculating effect size using Omega-squared, the value indicates that about $1 \%$ of the difference between the groups of students can be explained by diploma type.

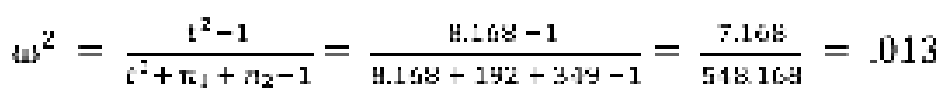

In calculating effect size using Cohen's $d$, the value indicates that the effect size is small. 


$$
u=\frac{\left(s_{1}-i i_{2}\right)}{s_{t s}}=\frac{(1.063-3.1: 4)}{2.513}=.256
$$

IB Diploma candidates $(n=188)$ were accepted to $49.75 \%$ of the schools to which they applied $(S D=0.267 ; S E M=0.019)$. IB Certificate candidates $(n=323)$ were accepted to $54.52 \%$ of the schools to which they applied $(S D=0.312 ; S E M=0.017)$.

Independent $t$ test for equality of means shows a mean difference between the two groups of 0.047 acceptances. The $t$ test failed to reveal a statistically reliable difference between the mean percentage of college acceptances for the IB Diploma candidates $(M=0.498, s=0.267)$ and the IB Certificate candidates $(M=0.5442, s=0.313), t(511)=1.791, p=.074$, $\alpha=.05$.

Based on school data results from the National Clearinghouse's StudentTracker for High Schools aggregate report, 362 of the seniors (approximately 67\% of the total sample) in the Classes of 2007-2012 matriculated to higher education in the United States to a college or university that reports attendance data to the U.S. Department of Education through the National Clearinghouse. Of that group, 116 IB Diploma candidates (32\% of the total group and $90 \%$ of the diploma candidates) and 195 IB Certificate candidates (54\% of the total group and $84 \%$ of the certificate candidates) matriculated in college the fall directly following graduation. For both groups combined, $86 \%$ of the schools' graduates matriculated directly to a college represented by the National Clearinghouse the fall immediately following graduation. Within the first year after graduation, five more diploma candidates (4\%) and 27 certificate students $(12 \%)$ had matriculated in college, and within 2 years after high school graduation, an additional eight diploma candidates $(6 \%)$ and 11 certificate students (4\%) matriculated in a college represented by the Clearinghouse report. The Pearson's Chi-Square test demonstrated a value of 6.308 and an asymptotic significance of 0.043 . This shows the difference between the time that it took for IB Diploma candidates and IB Certificate candidates to enroll in college was statistically significant at the $p=.05$ level.

According to the Chi-square test, a significant relationship was found between diploma type and college matriculation rate, $\chi^{2}(2, N=362)=$ $6.308, p=.043$.

Of the 362 students from the study school who matriculated in a college represented by the National Clearinghouse, 304 of those students have been in college long enough to measure freshman-to-sophomore persistence. One hundred and six IB Diploma candidates (29\% of the total group of 362 students and $93 \%$ of all diploma candidates) attended the same 
college from their freshman year to sophomore year and had no time lapse in attendance from spring semester of their freshman year to fall semester of their sophomore year. (Summer school data was not included as part of this study.) One hundred eighty-two certificate students $(60 \%$ of the total group of 362 students and $94 \%$ of all certificate candidates) attended the same college from their freshman year to sophomore year and had no time lapse in attendance from spring semester of their freshman year to fall semester of their sophomore year. For the students who did not remain in a college represented by the Clearinghouse from their freshman year to sophomore year, four students were IB Diploma candidates (3.63\% of the DP group) and 12 students were IB Certificate candidates $(2.36 \%$ of the certificate group).

A Chi-square test was performed and no significant relationship was found between diploma type and college retention rate, $\mathrm{X}^{2}(2, N=362)=$ $1.170, p=.557$.

Table 2. Diploma and certificate mean graduation timespan and percentages, 2007-2008.

IB diploma candidates

4.00 years

Class of 2007: Mean

length of time spent in

college before graduating

Class of 2007: Percentage

of group with a college

degree in 2012

Class of 2008: Mean

length of time spent in

college before graduating

Class of 2008: Percentage

of group with a college

degree in 2012

$59 \%$

3.86 years
IB certificate candidates

4.33 years

$19 \%$

4.00 years

Note. IB = international baccalaureate.

Since the study school has only had IB graduates since 2007 , this study analyzed the college graduation information for the Classes of 2007 and 2008 that was available through the National Clearinghouse. As illustrated by the information in Table 2, the data report for the Class of 2007 contained 80 students (32 diploma students and 48 certificate 
students). At the time of the study, 19 diploma students (59\% of the diploma group) and 15 certificate students (19\% of the certificate group) in the class had completed a bachelor's degree from a U.S. college or university which reports graduation data to the National Clearinghouse. The mean length of time spent in college before graduation for IB Diploma candidates in the Class of 2007 was 4.00 years $(S D=0.471)$, and the mean length of time for certificate students was 4.33 years $(S D=0.617)$.

For the Class of 2007, the $t$ test failed to reveal a statistically reliable difference between the mean length of time spent in college before graduating for the IB Diploma candidates $(M=4.00, s=0.471)$ and the IB Certificate candidates $(M=4.333, s=0.617), t(32)=1.731, p=.096, \alpha=$ .05 .

The data report for the Class of 2008 contained 84 students (28 diploma students and 56 certificate students). At the time of this study, nine diploma students (32\% of the diploma group) and 15 certificate students ( $27 \%$ of the certificate group) in the class had completed a bachelor's degree from a U.S. college or university that reports graduation data to the National Clearinghouse. The mean length of time spent in college before graduation for IB Diploma candidates in the Class of 2008 was 3.86 years $(S D=0.378)$, and the mean length of time spent in college before graduation for certificate students was 4.00 years $(S D=0.00)$.

For the Class of 2008, the $t$-test failed to reveal a statistically reliable difference between the mean length of time spent in college before graduating for the IB Diploma candidates $(M=3.857, s=0.378)$ and the IB Certificate candidates $(M=4.00, s=0.00), t(20)=1.00, p=.356, \alpha=.05$.

At an IB school that offers a two-track program for high school juniors and seniors, the decision to follow a full diploma or certificate path toward graduation involves a great deal of contemplation, investigation, and input from teachers and others who are aware of a student's strengths and weaknesses academically. The results of the data analysis for this specific school show that when it comes to college acceptances and eventual college completion, a student's status in high school as a full IB Diploma candidate or an IB Certificate student is not necessarily an accurate predictor or indicator of the level of success after graduation in the world of higher academia. The results of this research do not provide a definite answer to the role a specific IB course of study in high school plays in the college acceptance and college completion process.

What the data did show is for this school, IB Diploma students submit a higher number of college applications than their certificate peers (a mean difference of 2.068 more), but their college acceptance rate was not 
significantly higher than their certificate peers. This could be a result of IB Diploma candidates applying to more selective schools overall, but this was not a factor addressed as part of this study. It is also true for graduates in the Classes of 2007-2012; all 10 of the school's Ivy League acceptances were for students who were pursuing the IB Diploma.

The other important note is for all graduates of the study school between 2007 and 2012, the college completion rate is high. The school should be commended in the fact that all students, whether IB Diploma or IB Certificate candidates, showed a high level of preparedness for college in their matriculation, retention, and graduation rates. This implies the strength of the entire program at the school is strong and their high school graduates enter the world of higher education in the United States equipped with the academic skills necessary to be successful.

Perhaps the most important point of the study is the college application and graduation process for international students and domestic students is multi-faceted and contains a number of variables. One of those variables may be the course of study a student pursues in high school, like an IB Diploma or Certificate path, for example. However, to say a specific academic path is the only way to achieve success in college is not a statement that can be supported by the data results from this specific study.

The hypotheses of this study were that there would be a statistically significant difference in the college application rates, acceptance rates, retention rates, and graduation rates between the students who participated in the full IBDP compared to students at the same school who participated in the IB Certificate program. The results of the analyses revealed no statistically significant difference existed between the two groups of students in their college acceptance rates, retention rates, and graduation rates.

\section{DISCUSSION AND CONCLUSIONS}

This study examined college application, retention, and graduation data for one private international school in East Asia that uses the IB curriculum. Comparison studies with other IB World Schools in different areas who offer both the diploma path and certificate path could provide more information to show if the college trends seen at the study school are similar or different by school or region. Because this study was only able to examine college graduation data for high school graduates at the study school from the Classes of 2007 and 2008, a follow-up study of college 
graduation rates for additional classes of graduates after more time has elapsed would provide a more thorough analysis of trends over time.

There were four factors not addressed as part of this study that could also potentially have a significant effect on the length of time students spend in college before graduating: (a) How might a specific major in college or degree type take longer to complete than another major or degree type? (b) Do IB Certificate students select majors that can be completed faster than majors chosen by IB Diploma students? (c) In international schools which educate Korean students, how does mandatory military service for Korean males delay college graduation? and (d) Do IB Diploma recipients receive more college credit granted as a result of their IB coursework, and do they therefore not have to complete as many credits in college to graduate, resulting in less time in college before graduation? These factors could potentially skew graduation rates and could be addressed as part of a future study.

Other important factors in the college admission process that were not incorporated into this specific study include high school cumulative grade point average (GPA) for students in the two groups and the selectivity rates of the schools to where students apply. These two elements could be addressed as part of future studies and may indicate more specific trends for the two types of IB students.

The IBO collects and analyzes a tremendous amount of data each year for IB Diploma candidates ("IB Statistical Bulletin,” 2016). However, they do not maintain or analyze information on IB Certificate candidates, or even have a record of which schools worldwide offer both options for their students. This presents a significant gap in data and understanding of the two cohorts of learners, and an effort should be made on the part of the IBO to track data for both groups of students worldwide.

\section{IMPLICATIONS}

Too often in education circles throughout the world, well-meaning teachers, administrators, parents, and policy makers make decisions or develop ideas that are based on assumptions and are not necessarily based on data. Number crunching and data collection takes time and effort, but the results offer concrete answers, and these answers are necessary to build strong educational systems. This study was born out of an assumption at the study school that IB Diploma candidates will have higher college acceptance rates and will be more prepared to be successful in college. The design of the study was to take data that was readily available and see if that assumption 
was accurate. In this case, based on a statistical analysis, the assumption was incorrect and there is not a significant difference between the two groups in the areas that were analyzed.

International students across the world have a tremendous amount to offer colleges and universities in the United States. Their presence can enhance and enrich a college campus and bring a spirit of diversity and global perspective to classrooms in every major field of study. International secondary schools are often challenged to provide an avenue down which students can access U.S. higher education. Having concrete data to share with students, parents, staff, and stakeholders empowers not only the school guidance office, but it gives freedom to students to choose the paths that are best for them-based on their strengths and goals for the future.

\section{REFERENCES}

Adelman, C. (2006). The toolbox revisited: Paths to degree completion from high school through college. Washington, DC: U.S. Department of Education.

Bergeron, L. (2015). Diploma Programme students' enrollment and outcomes at US postsecondary institutions 2008-2014. Bethesda, MD: International Baccalaureate Organization.

Borden, J. (2005). Confucius meets Piaget: An educational perspective on ethnic Korean children and their parents (3rd ed.). Seoul, Korea: Author.

Breland, H., Maxey, J., Gernand, R., Cumming, T., \& Trapani, C. (2002). Trends in college admission 2000: A report of a national survey of undergraduate admissions policies practices, and procedures. Retrieved from www3.airweb.org/images/trendsreport.pdf

Bunnell, T. (2008). The global growth of the International Baccalaureate Diploma Programme over the first 40 years: A critical assessment. Comparative Education 44(4), 409-424. doi: 10.1080/03050060802481439

Caspary, K. (2011). Research brief: Postsecondary enrollment patterns of IB certificate and diploma candidates from international high schools. Menlo Park, CA: SRI International. Retrieved from http://www.ibo.org/research/ programmevalidation/documents/IBSuppInternationalResearchBrief201105-06.pdf

Caspary, K., \& Bland, J. (2011). Research brief: First college courses taken by Florida IB students. Menlo Park, CA: SRI International. Retrieved from http://www.ibo.org/research/programmevalidation/documents/FLcoursesre searchbrief2011-04-06.pdf

Chen, C. (1999). Common stressors among international college students: Research and counseling implications. Journal of College Counseling, 2(1), 49-65.

Chmelynski, C. (2005). International Baccalaureates just keep growing in the U.S. Education Digest, 70(5), 58-61. 
Duevel, L. (1999). The International Baccalaureate experience: University perseverance, attainment, and perspectives on the process (Doctoral dissertation). Purdue University, Indiana.

Retrieved from http://docs.lib/purdue.edu/dissertations/aai9951943/

Gazda-Grace, P. (2002). Psst... Have you heard about the International Baccalaureate Program? Clearing House, 76(2), 84-87.

Gehring, J. (2001). The International Baccalaureate: "Cadillac" of college prep programs. Education Week, 32(April 25). Retrieved from http://www.edweek.org/ew/articles/2001/04/25/32ib.h20.html

Geiser, S. (2008, August). Back to the basics: In defense of achievement (and achievement tests) in college admissions. Paper presented at the meeting of Center for Enrollment Research, Policy and Practice, University of Southern California, Los Angeles, California. Retrieved from www.usc.edu/programs/ cerpp/docs/GeiserPaper.doc

Geiser, S., \& Santelices, V. (2004). The role of advanced placement and honors courses in college admissions. Center for Studies in Higher Education, University of California, Berkeley, California.

IB Diploma Programme Statistical Bulletin. (2016, May). Retrieved from http://www.ibo.org/about-the-ib/facts-and-figures/statistical-bulletins/ diploma-programme-statistical-bulletin/

International Baccalaureate Organization. (2017). About the International Baccalaureate. Retrieved from http://ibo.org/en/about-the-ib/

Kim, J. (2011). Aspiration for global cultural capital in the stratified realm of global higher education: Why do Korean students go to US graduate schools? British Journal of Sociology of Education, 32(1), 109-126.

Mayer, A. P. (2008). Expanding opportunities for high academic achievement: An International Baccalaureate Program in an urban high school. Journal of Advanced Academics, 19(2), 202-235.

National Student Clearinghouse. (2012). StudentTracker for high schools aggregate report.

National Student Clearinghouse Research Center. (2017). StudentTracker for high schools. Retrieved from http://www.studentclearinghouse.org/colleges/ studenttracker/

Naviance. (2017). College and career readiness platform. Retrieved from https://www.naviance.com/solutions/high-schools

Park, E. L. (2009). Analysis of Korean students' international mobility by 2-D model: Driving force factor and directional factor. Higher Education, 57, 741-755. doi: 10.1007/s10734-008-9173-x

Shah, S., Dean, M., \& Chen, Y. C. (2010). Academic performance of IB students entering the University of California System from 2000-2002. Geneva: IBO.

Taylor, M. L., \& Porath, M. (2006). Reflections on the International Baccalaureate Program: Graduates' perspectives. The Journal of Secondary Gifted Education, 17(3), 21-30. 
Thomas, P. B. (1991). Research project recognition of the IB Diploma: Progress report (Internal). Geneva, Switzerland: International Baccalaureate Organization.

Zhang, Y., \& Hagedorn, L. (2011). College application with or without assistance of an educational agent: Experience of Chinese undergraduates in the U.S. The Journal of College Admissions, 212(3), 6-16.

JENNIFER COLES HILL, EdD, LPC, is an Assistant Professor of Education. She currently coordinates the secondary education program at Northwest Nazarene University in Nampa, Idaho. In addition to a focus on K-12 education practices and policy, Dr. Hill has a passion for college and career counseling with secondary students of all backgrounds. Email: jjhill@nnu.edu 